\author{
DANIEL SCHÁVELZON
}

\title{
Rafael Yela Gunther \\ y Manuel Gamio en Teotihuacan: \\ una historia desconocida para el arte y la arqueología mexicanos
}

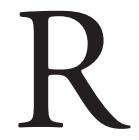

ecientemente se reinauguró el Auditorio de Teotihuacan. Tras años de estar fuera de uso fue reparado y nuevamente comenzó a prestar los servicios para los que había sido pensado hace más de ochenta ańos: actividades culturales dirigidas a la comunidad. Esto es loable y un hito en la historia de las ruinas en sí mismas, ya que se relaciona íntimamente con la forma en que se hizo arqueología en ese entonces - en el muralismo mexicano de la década de 1920 - y a la forma en que se pensó el vínculo entre comunidad local, cultura y ciencia.

Generalmente todos hemos pensado — sin sustento alguno- que, como tantas otras obras en el sitio, el Auditorio había sido creado "por" Manuel Gamio, y que la obra concreta debió proyectarla el arquitecto que trabajaba con él en forma habitual en las restauraciones: Ignacio Marquina. Sin embargo, ninguno de los dos se ha atribuido ese edificio, aunque tampoco han revelado quién lo levantó. Gamio, en sus múltiples escritos sobre Teotihuacan, no escribió casi sobre las obras de infraestructura en que intervino y que fueron muchas, como el museo reorganizado, la escuela, el jardín botánico, los canales de riego, el horno de cerámica, la reutilización de las canteras de obsidiana para los nuevos talleres artesanales, la ceramoteca, el auditorio, las bombas a la napa freática, la modificación de la vieja casa de Leopoldo Batres, el uso del lugar para el deporte juvenil. De todo ello no se escribió nada. No sólo es intrigante de por sí, sino que una observación detallada muestra que en realidad el Audi- 
torio — que es lo que deseamos destacar aquí- es mucho más que un simple lugar para ver espectáculos, pues fue un espectáculo en sí mismo, una obra del nuevo muralismo de su tiempo con características insólitas, a tal grado que en apariencia nadie fue consciente de su singularidad: fue hecho para mirar y ser visto a la vez.

Al parecer, hasta donde he logrado reconstruir la historia de ese complejo conjunto, al igual que varias otras obras de Teotihuacan, fue creado por Rafael Yela Gunther (1888-1943), escultor guatemalteco nacido en Quetzaltenango e hijo de otro escultor muy poco conocido que tuvo una larga relación con México.

Durante los años del gran proyecto antropológico y arqueológico de Manuel Gamio, ${ }^{\mathrm{I}}$ como es de suponer, además del personal estable en el sitio había jóvenes (y no tan jóvenes) mexicanos y de todo el mundo que se acercaron y participaron de diversas maneras, a veces durante cortas estadías; algunos incluso no fueron aceptados o no quisieron quedarse ${ }^{2}$ y muchos artistas sólo fueron a crear sus obras. La historia del Auditorio es justamente la de uno de los jóvenes que sí se quedaron allí: Rafael Yela Gunther, quien colaboró con Gamio en México entre I92I y 1925, y luego se trasladó con él a excavar las ruinas de Kaminaljuyú, Guatemala, en 1926, y en seguida a Estados Unidos, para regresar más tarde cada uno a su país, ambos tras profundos cambios en sus formas de pensar y de actuar, en especial en cuanto a política.

Esta relación la encontré por casualidad al escuchar en Guatemala una conferencia de Luis Luján Muñoz, ${ }^{3}$ quien estaba por publicar la biografía de este poco conocido arqueólogo, arquitecto, escenógrafo y artista. ${ }^{4}$ Gracias a esa pista fue posible iniciar conversaciones y estudios para tratar de identificar al autor de la obra aquí comentada.

Yela fue uno de los miembros de la generación de Los Modernos que a principios del siglo xx intentaron marcar un nuevo rumbo en el arte de Gua-

I. Eduardo Matos Moctezuma, Manuel Gamio: arqueología e indigenismo, México, Secretaría de Educación Pública (Sepsetentas), 1972.

2. Daniel Schávelzon y Jorge Tomasi, La imagen de América: los dibujos de Francisco Mujica Diez de Bonilla, Buenos Aires, famsi-Fundación Ceppa, 2005.

3. Conferencia dictada por Luis Luján Muñoz en la Academia de Geografía e Historia de Guatemala en octubre de 1982; los datos aquí incluidos provienen de comunicaciones personales con él en los siguientes años.

4. Luis Luján Muñoz, "Carlos Mérida, Rafael Yela Gunther, Carlos Valenti; Sabartés y la plástica contemporánea en Guatemala", Anales de la Academia de Geografia e Historia, Guatemala, vol. LVIII, I982, pp. 267-299. 
temala, formando un primer grupo junto con Carlos Mérida y Carlos Valenti. Nacido en I888, fue dibujante, pintor, escultor, escenógrafo, arquitecto y arqueólogo por afición, aunque lo más perdurable de su obra han sido sus esculturas urbanas. Viajó en I92 I a México — destino obligado de casi todo intelectual en esos tiempos-, donde se puso en contacto con Gamio, quien, cargado de ideología de la Revolución, desde I9I7 desarrollaba su proyecto interdisciplinario en Teotihuacan. Entonces comenzó a trabajar allí en diversas tareas y se encargó de la gran obra del Auditorio, de producir los murales que decorarían el museo reordenado y de realizar por lo menos una gran escultura. En cuanto al Auditorio, además de construirlo, debía ocuparse de que estuviera ampliamente decorado a la moda, es decir con motivos de la tradición indígena o "tipo prehispánico". Es evidente que conocía a Diego Rivera y, por lo que llegó a decir de él y su obra, que coincidía claramente con la corriente estética y social de ese artista.

Yela siguió trabajando en México después de terminado el proyecto, en la ya ex Secretaría de Antropología, hasta que Gamio salió del país en medio de polémicas provocadas por denuncias de soborno a sus superiores. En este caso, la historia avanzó al revés de lo tradicional: fue la del mexicano que busca refugio en Guatemala, donde Yela y Gamio participaron en el trabajo arqueológico emprendido en las ruinas de Kaminaljuyú. En realidad sabemos que Gamio partió primero hacia Nueva York y que, tras diversos contactos con las universidades, consiguió trabajo en Guatemala, donde comenzaba una temporada de excavaciones. 5 También, que llevó a Yela Gunther como su ayudante - los unió una relación clara de jefe y secretario privado—y que, quizás por eso el episodio no figura en sus biografías. Allí, durante 1926, hicieron una serie de pozos estratigráficos en la finca Miraflores, lo que sirvió para que Alfred Kidder comenzara a excavar en el sitio al año siguiente en forma sistemática.

Más tarde, ya de regreso en Estados Unidos, ambos trabajarían con Edgard Hewett, quien ya era un gran arqueólogo en aquel país. Es muy posible que la relación de Gamio con Hewett, director de la Escuela de Estudios Americanos entre sus muchos cargos y logros durante el gobierno de Roosevelt -al que apoyó- viniera de mucho antes. Recordemos que Hewett había excavado en Quiriguá, Guatemala, entre I9I0 y 1913, y que sus discípulos mesoamericanistas más conocidos eran Sylvanus Morley y el citado Alfred Kidder, por lo que

5. Ángeles González Gamio, Manuel Gamio, una lucha sin final, México, Universidad Nacional Autónoma de México, 1987. 
seguramente tendría un especial interés por Guatemala. Morley, durante los años de Gamio, había planeado su gran proyecto en Chichén Itzá.

Mientras tanto, Yela seguía dibujando y pintando, imbuido de las ideas neoprehispánicas e indigenistas de su tiempo. En 1924, poco antes del exilio voluntario, Diego Rivera escribió acerca de él: "Yela Gunther es el mejor elemento con que la plástica escultórica cuenta en este momento en México", lo cual era mucho decir cuando procedía de alguien que no era pródigo en elogios, aunque sí bastante exagerado. ${ }^{6}$ Un año más tarde, su gran relieve en cerámica Una familia camino al mercado fue muy halagado por Jean Charlot, en estos términos:

la técnica empleada en él es tan simple como el motivo; los planos sobriamente contrastados; los sutiles claro-oscuros se hermanan con la sencillez del tema. Así como el lenguaje heroico no conviene a los cuentos de nińos, así la materia plástica debe subordinarse al sujeto tratado. Yela ha empleado la greda como la pudieron haber empleado los mismos indios que él representa en el relieve, dando con una sencillez bien grande, la sensación de volúmenes y planos [...] Este bajo relieve (4 metros o 3.50 metros de ancho) quedará sin duda como uno de los grandes aciertos de nuestras especulaciones actuales para acercarnos a las fuentes puras del arte y hacernos olvidar nuestros prejuicios y juglerías de civilizados decadentes. Y bien merecería llamarse, por el espíritu que lo anima, Bucólica Mexicana. ${ }^{7}$

Para el Museo Nacional, Yela modeló varias cabezas indígenas que seguramente se conservan en algún lugar del depósito y quizás muchas obras más de las que no hay registro.

Yela vivió en Estados Unidos de 1927 a 1930, año en que regresó a México como agregado cultural en la embajada de su país; parece que el cambio político le favoreció y que poco más tarde volvió a Guatemala para ser, desde 1935, director de la Academia de Bellas Artes hasta su fallecimiento en 1942. Allí, rehízo todos los programas de estudio, tratando de actualizarlos en la medida de la situación imperante. Fallecería al ańo siguiente, a los 60 de edad. Con relación a él y al dictador Ubico, es poco lo que podemos decir, ya que resulta un tema en extremo complejo respecto al que se expresan opiniones muy

6. Diego Rivera, El Demócrata, México, 2 de enero 1924.

7. Jean Charlot, Escritos sobre arte mexicano, Peter Morse y John Charlot (eds.), J. Charlot Foundation, 2000. www.hawai.edu/jef 
diversas; Ubico y él fueron contemporáneos - aquél estuvo en el poder de I93I a I944 y murió en I946- y originarios de la misma ciudad. Pero de lo que no hay duda es de que Yela participaba con Gamio de una ideología marcada por la revolución mexicana, mientras que por otra parte Ubico no sólo fue un genocida, sino que persiguió toda forma de cultura de vanguardia, en especial el muralismo mexicano y sus ideas libertarias. También es cierto que el arte fue uno de los pocos refugios en que algunos intelectuales pudieron sobrevivir; el tema queda abierto a futuros estudios.

En su ciudad natal, luego de su regreso, produjo dos grandes esculturas públicas, la más conocida de las cuales es el monumento dedicado a Justo Rufino Barrios, de unos I5m de altura. También difundió su tardío y difuso mensaje pseudorrevolucionario vía la educación y el desarrollo de la industria. Es probable que en esos años, cuando el dictador Ubico — quien fue además jefe político de Quetzaltenango- inauguró el monumento, poco quedaba ya de su ideología juvenil, si es que la tuvo, como artista de la Revolución. O quizá experimentó el mismo cambio mental que su jefe, o al menos aceptó con mayor pragmatismo la realidad, amoldándose a ella sin querer cambiarla. En Quetzaltenango creó más tarde un monumento dedicado a Benito Juárez. De su arquitectura, creemos que nada pasó del proyecto.

La oración fúnebre a su muerte la leyó ni más ni menos que Miguel Ángel Asturias,${ }^{8}$ quien era ya un hombre conocido. En la ciudad de Guatemala, donde Yela fue director de la entonces Academia, dictó sólo las clases de escultura. Ahí se encuentran, entre otras obras suyas, El Obelisco, una imagen de Cristo en la Capilla de la Penitenciaría y el Monumento al Trabajo ubicado en La Palmita.

La obra de Yela Gunther era interesante y suscribía las búsquedas propias de su tiempo. Este artista pudo colaborar y participar con los muralistas, aunque no era Rivera ni Orozco, ni tampoco Siqueiros con sus compromisos políticos. Posiblemente, Yela poseía una personalidad muy distinta y eso lo puso bajo la dirección de alguien como Gamio, la gran figura de su época; si fuera necesario buscar alguna analogía de su tiempo, estaba quizás más cerca de las contradicciones de Charlot que de cualquier otro conocido. Pero la mano del destino fue implacable: Gamio fue desplazado de su sitial y Yela debió irse con él; y luego, cada uno regresó a su país, aunque ya golpeados, para rearmar su trayectoria

8. Miguel Ángel Asturias, “Oración fúnebre pronunciada en homenaje a Rafael Yela Gunther”, El Liberal Progresista, Guatemala, I8 de abril de I942, p. 2. 
de la mejor forma posible. De su grupo inicial sólo Carlos Mérida, radicado por años en México, logró una obra que trascendió las fronteras y que también es parte de la compleja historia de la relación entre Guatemala y México. Yela quedó en un segundo plano, pues su contada pintura es apenas conocida, sus esculturas no salen de lo habitual de la generación de 1920, no escribió ni publicó nada, y salvo por el Auditorio, poco se le conoce por lo que su obra quedó también en un honroso segundo lugar, quizá como el sitio que la sociedad le asignó, al lado de Gamio, al no tener ni los contactos ni el dinero ni las relaciones sociales de este último, al menos hasta que en 1935 pudo tener el puesto de director de la Academia, y seguramente eso debió tener algún precio.

\section{Rafael Yela Gunther en Teotihuacan}

Hemos dicho que a su llegada a México se puso en contacto directo con Gamio, como artista y dibujante, mas no como arqueólogo, y que con él trabajó varios años. Su obra magna fue sin duda el Auditorio, que, pese a ser a cielo abierto, no es tan simple como ahora parece: el sitio fue elegido cuidadosamente y no sólo por estar a un lado del edificio de la escuela-taller que Gamio creó, donde aún el horno de cerámica está entre ambas construcciones, aunque abandonado pese a que hoy es el Centro Regional del Instituto Nacional de Antropología e Historia. Quien observe este teatro abierto verá que el lugar está bajo el nivel del suelo exterior en un área donde la lava fue excavada antiguamente, dándole así una excelente acústica; la lava en los lados apaga muy bien la reverberación del sonido gracias a su textura, y la belleza de la piedra desnuda y las pequeñas grutas es impresionante. Se edificó precisamente contra una cortina de piedra, un telón natural magnífico que realza el semicírculo de bancas sencillas que conforma el Auditorio en la mejor tradición grecolatina. Unos enormes cardones de cemento con forma de columnas con grandes vasijas de doble asa marcan los accesos, imprimen verticalidad al conjunto y ubican la obra en la corriente estilística del art decó de su tiempo.

Las bancas estaban totalmente pintadas de color crema — no blanco- - y en la parte posterior de ellas Yela Gunther hizo murales sencillos de color rojo oscuro similar al de las pinturas de los edificios teotihuacanos, logradas con pigmentos naturales; los motivos eran abstractos e imitaban ligeramente algunas indefinidas formas del sitio. Una escultura monumental, un tlahuicole que posa relajado, miraba de frente a los actores desde atrás de las bancas. 
La gran obra allí era el gigantesco mosaico que cubre todo el piso del sitio, a tan gran escala que muchos no lo ven: hecho con piedra bola gris y tezontle rojo, forma serpientes entrelazadas entre las bancas, grecas, plantas y hasta un motivo en forma de arpa; cada zona era diferente de las otras. Para su tiempo, fue una obra inmersa en la corriente neoprehispánica o indigenista, ${ }^{9}$ tan significativa para la pintura mural impulsada desde poco antes por la Secretaría de Educación Pública. El Auditorio de Teotihuacán merece ser considerado fundante en el arte del nacionalismo mexicano y en especial del muralismo, aunque jamás haya sido nombrado cuando se habla de este último —o quizás porque - representó una búsqueda totalmente diferente de la de otros creadores. Por suerte, varias de las bancas lograron salvar sus pinturas del abandono destructivo y actualmente han sido recuperadas; también se ha perdido el muro curvo que cerraba el terreno. Los camerinos están aún en su sitio, y la lava y los árboles completan el conjunto como entonces, tal como lo consignó un diario en la fecha de la inauguración: "Como en la Ópera de París, los automóviles pueden llegar hasta muy cerca de los palcos, evitando así molestias a los espectadores". ${ }^{\circ}$

La construcción de este escenario para el teatro era parte de un plan más amplio que llevó a Gamio a filmar varias películas — ahora todas perdidas-en la zona, que se proyectarían allí mismo como mecanismo para recuperar la memoria local; incluso lo hizo a escala nacional. Sabemos que el teatro se inauguró en 1922 y hubo actividades en forma regular y proyección de cine, lo que debió ser impactante para los habitantes locales. ${ }^{\text {II }}$

En Teotihuacan el joven Yela Gunther produjo otras obras, lamentablemente destruidas en su mayor parte: el Tríptico de la Raza, mural en tres partes que decoraba el antiguo museo construido originalmente por Leopoldo Batres y al que Gamio modernizó con una nueva decoración cuyos esquemas ilustrarían su libro, y una gran escultura denominada El indio primitivo, cuya ubicación original desconozco y que seguramente ya no existe. Para algunos se trata posiblemente del enorme tlabuicole que mira hacia el auditorio, aún en su lugar.

En la publicación de la tan conocida obra La población del Valle de Teotihuacan tuvo alguna actividad como artista, pues diseñó entre otras cosas las portadas, ayuda que Gamio agradeció así en la introducción: "El señor Rafael

9. Daniel Schávelzon (coord.), La polémica del arte nacional en México: 1850-1910, México, Fondo de Cultura Económica, I988.

Io. Aurelio de los Reyes, Manuel Gamio y el cine, México, Universidad Nacional Autónoma de México, I99I.

I I. Ibidem, p. 86. 
Yela Gunther dibujó los grabados de las tres portadas, que sintetizan gráfica y simbólicamente la vida de la población teotihuacana en sus tres etapas evolutivas"; ${ }^{12}$ en realidad eran parte del gran mural del museo.

El Auditorio de Teotihuacan es así un triple monumento: una obra inscrita en una forma de entender el quehacer de la arqueología, que iba mucho más allá de la arqueología en sí misma; la única obra de arte de Yela Gunther que queda en el sitio, con la ventaja de ser todo un conjunto, y, sin duda, una obra interesante y diferente de los principios del muralismo en México —el mural es el piso mismo con sus bancas en relieve. Ahora, constituye una buena recuperación patrimonial con que se demuestra que no es necesario demoler, sino usar la imaginación, para rescatar el pasado, no importa cuán lejano o cercano esté de nosotros mismos. \$े

I2. Manuel Gamio, La población del Valle de Teotihuacan, México, Dirección de Agricultura, I922, vol. I, p. CII. 